\title{
Relaciones y condiciones laborales del trabajador social hoy: la proletarización de la profesión*
}

\author{
Relações e condições de trabalho do assistente \\ social na atualidade: a proletarização da profissão
}

\author{
Maria Angelina B. de Carvalho de A. Camargo ${ }^{a}$ \\ (D) https://orcid.org/0000-0003-1652-3992
}

Resumen: Este artículo presenta algunos de los caminos y "descubrimientos" investigativos de un estudio sobre las relaciones y condiciones laborales de los trabajadores sociales en el mercado de trabajo. Destaca las tendencias actuales para el poner en proceso de la acción profesional por medio de la tesis de la proletarización, que indica la precariedad, informalidad, intensificación y subcontratación del trabajo - objetivada en niveles salariales muy bajos, contratos temporales, subcontratación, espacios insalubres, sobrecargas, enfermedades y humillaciones.

Palabras-clave: Trabajo. Servicio Social. Mercado de Trabajo. Procesamiento de la Acción Profesional. Proletarización.
Resumo: Este artigo apresenta alguns dos percursos e "achados" investigativos de uma pesquisa** sobre as relações e as condições de trabalho de assistentes sociais no mercado de trabalho. Destaca as tendências em curso para o processamento da ação profissional através da tese da proletarização, que indica a precarização, a informalidade, a intensificação e a terceirização do trabalho -, objetivada em níveis salariais baixíssimos, contratos temporários, subcontratações, espaços insalubres, sobrecargas, adoecimentos e humilhações.

Palavras-chave: Trabalho. Serviço Social. Mercado de Trabalho. Processamento da Ação Profissional. Proletarização. 


\section{Introducción}

$\mathrm{E}$ ste artículo presenta la tesis de la proletarización del trabajo del trabajador social en tiempos de capital fetiche y profunda crisis estructural del capital, como una mediación para explorar el procesamiento ${ }^{1}$ de esta especialización del trabajo en el mercado. El eje de análisis son las relaciones y condiciones laborales en las instituciones empleadoras de carácter público, privado y filantrópico que prestan servicios en las áreas de seguridad social, educación y socio-jurídica. Para eso, se utiliza de la investigación bibliográfica y de campo para dilucidar la proletarización como tendencia contemporánea en el Trabajo Social, utilizando el eje categórico precariedad, informalidad, subcontratación (externalización), intensificación. El artículo está organizado en tres secciones: 1 . El capital fetiche y el mundo del trabajo; 2 . La tesis de la proletarización del trabajo del trabajador social; 3. Manifestaciones de proletarización en el trabajo profesional y conclusión.

\section{Capital fetiche y mundo del trabajo}

Marx ya señaló, en una etapa temprana, la tendencia cada vez mayor del capital ficticio a manifestarse en forma de propiedad monetaria (D - D') y a profundizar la alienación de la relación social de producción presidida por el capital, en la forma de capital que devenga interés.

Na forma do capital portador de juros, portanto, esse fetiche automático está elaborado em sua pureza, valor que valoriza a si mesmo, dinheiro que gera dinheiro, e ele não traz nenhuma marca de seu nascimento. A relação social está consumada como relação de uma coisa, do dinheiro consigo mesmo. Em vez da transformação real do dinheiro em capital aqui se mostra apenas sua forma sem conteúdo. Como no caso da força

Procesamiento es la forma como se efectiva, en cuanto trabajo concreto, la actividad laboral del trabajador social asalariado. (N.T.) 
de trabalho, o valor de uso do dinheiro torna-se aqui o de criar valor, valor maior que o contido nele mesmo [...] de tal modo que proporciona o juro não como capital funcionante, mas como capital em si, como capital monetário (MARX, 1986, p. 294). ${ }^{2}$

Esta tendencia, en forma de capital monetario que devenga intereses, distorsiona no solo el interés como parte de la ganancia, sino que también hace que parezca que el interés es el resultado del capital aisladamente o "una relación entre dos capitalistas y no entre capitalista y trabajador" (Ibíd.; 285). El propósito es llevar a cabo el "intercambio de piel” para translucir el capital como:

coisa, mas como coisa capital. O dinheiro tem agora amor no corpo. Tão logo esteja emprestado ou também investido no processo de reprodução (desde que proporcione ao capitalista funcionante, como seu proprietário, juros separadamente do ganho empresarial), acresce-lhe juro, esteja dormindo ou acordado, em casa ou em viagem, de dia ou de noite. Realiza-se assim no capital monetário portador de juros [...] o desejo impiedoso do entesourador (MARX, 1986, p. 295). ${ }^{3}$

2 Este pasaje en la versión del editorial Siglo XXI: "En el capital que devenga interés, por consiguiente, este fetiche automático - el valor que se valoriza a sí mismo, el dinero que incuba dinero - se halla cristalizado en forma pura, en una forma en la que ya no presenta los estigmas de su origen. La relación social se halla consumada como relación de una cosa, del dinero, consigo misma. En lugar de la transformación real de dinero en capital, sólo se presenta aquí su forma carente de contenido. Al igual que en el caso de la fuerza de trabajo, en este caso el valor de uso del dinero se convierte aquí en el de crear valor, un valor a mayor que el que se halla contenido en sí mismo. [...] el capital realmente actuante se presenta a sí mismo de tal manera que arroja el interés no como capital operante, sino como capital en sí, como capital dinerario. (MARX, Karl. El Capital, tomo 3, vol.7, 1977: p.500-501 — traducción León Mames) (N.T.)

3 "El capital es ahora una cosa, pero en cuanto cosa es capital. El dinero tiene ahora dentro del cuerpo el amor. En cuanto se lo presta o incluso se lo invierte en el proceso de reproducción (en la medida en que arroja un interés, separado de la ganancia empresarial, para el capitalista actuante, en su condición de propietario de ese capital), sus intereses se acrecientan en él, hállese dormido o despierto, en su casa o de viaje, día y noche. De este modo, en el capital dinerario que devenga interés (y todo capital es, de acuerdo con su expresión de valor, capital 
Este deseo despiadado de acaparamiento/atesoramiento refleja el proceso de revalorización del capital en la figura autónoma que asume el interés en la dinámica capitalista actual. Para Marx (1986), el interés, en la figura particular de la ganancia, no es más que la plusvalía producida por el trabajador, no a través del trabajo concreto, sino del trabajo abstracto.

En el capitalismo contemporáneo, Chesnais (2005, p. 35) señala que el capital que devenga intereses está en el centro de las relaciones sociales y económicas, a través de la existencia de grupos industriales y transnacionales que controlan la producción social. Estos grupos "se encargan de organizar la producción de bienes y servicios, captar el valor y organizar directamente la dominación política y social del capital frente a los asalariados". Es una estructura compleja, cuyo papel de las instituciones financieras bancarias y no bancarias es fundamental para imponer el dominio burgués del tiempo presente, en que:

el capital busca "hacer dinero" sin salir del ámbito financiero en forma de intereses sobre préstamos, dividendos y otros pagos recibidos por la propiedad de acciones y, finalmente, ganancias nacidas de una especulación exitosa. Su campo de acción son los mercados financieros integrados a nivel nacional y interconectados a nivel internacional. Sus operaciones también se basan en cadenas complejas de crédito y deuda, especialmente entre bancos (Ibid.; p. 35).

Este rasgo determinante es la forma en que el capital que devenga interés impone una era de especulación, como mecanismo para su autovaloración. Para tanto, es fundamental intensificar la explotación del trabajo, su precariedad a niveles más degradados e inhumanos. Para eso, nuevas formas de control, gestión y organización del trabajo son vitales para la producción global de la producción capitalista, ya que el capital ficticio no puede renunciar a la base productiva.

dinerario, o se lo considera ahora como la expresión del capital dinerario) se han realizado los más caros anhelos del atesorador”. (ibíd.: 502) (N.T.) 
En estos términos, el mundo del trabajo se convierte en un territorio de reestructuración permanente y el florecimiento de las tecnologías de la información y comunicación (TICs) parecen ser un elemento nuevo $y$ central (Antunes, 2018) en la actualidad. A través de ellas, es posible reconfigurar los medios y formas de realizar el trabajo en las condiciones más adecuadas para el proceso de valorización del capital.

Estos procesos revelan el grado de desarrollo del capital como relación social de producción y el dominio de la ciencia, de la tecnología y del trabajo vivo -; elevando la productividad laboral, reduciendo el tiempo de trabajo socialmente necesario y prolongando el tiempo dedicado a la valorización del capital. Haciendo hincapié en los sufrimientos, los alejamientos y la fetichización de las relaciones sociales de producción en el mundo del trabajo.

Dicho esto, es importante que consideremos las nuevas condiciones y relaciones salariales en curso en el mundo del trabajo en sus tendencias globales. Actualmente, los procesos de uberización e intermitencia del trabajo se han convertido en una característica definitoria.

Veamos qué dice Abílio (2020, p. 112) sobre la uberización:

La uberización del trabajo define una tendencia en curso que puede ser generalizable por las relaciones laborales, que engloba a diferentes sectores de la economía, tipos de ocupación, niveles de calificación y ingresos, condiciones laborales, en nivel global. Derivado del fenómeno social que ganó visibilidad con la entrada de la empresa Uber en el mercado, el término uberización en realidad se refiere a procesos que ni se restringen a esta empresa ni se inician con ella, y que culminan en una nueva forma de control, gestión y organización del trabajo.

Como parte de este proceso, la intermitencia se manifiesta como "uno de los elementos más corrosivos de la protección del trabajo" (Antunes, 2020, p. 11), coloreando la explotación de la fuerza laboral.

La uberización como tendencia tiene como objetivo hacer las relaciones laborales más individualizadas e invisibles, según el autor. Estos 
fenómenos señalan el fin de una era de gestión de la fuerza laboral centrada en el trabajo regulado, con vínculo formal y duradero para que proliferen nuevas relaciones en las cuales el núcleo es la desregulación de la protección, transformando el trabajo en ocasional y sin garantías. Se destaca el papel activo del Estado en la concretización de tales fines, situando las relaciones de compra y venta de la fuerza de trabajo en un nuevo nivel de realización, dadas sus funciones de legislador y regulador de las relaciones sociales burguesas, agente vital en el ámbito de la reproducción social.

El ingreso y permanencia en el mercado laboral se modifica progresivamente, con formas más precarias y desproveídas de medidas de protección, estando presente la tercerización, la informalidad, la flexibilización en las relaciones laborales. Es una tendencia global que solo acentúa la degradación del trabajo;

El trabajo que caracteriza nuestro tiempo está marcado por:

por miles de millones de hombres y mujeres que dependen exclusivamente del trabajo para sobrevivir y se encuentran cada vez más en situaciones inestables, precarias o experimentando directamente el flagelo del desempleo. Es decir, al mismo tiempo que aumenta el contingente de trabajadores y trabajadoras a escala global, hay una inmensa reducción de puestos de trabajo; los que quedan empleados presencian la corrosión de sus derechos sociales y la erosión de sus logros históricos, consecuencia de la lógica destructiva del capital [...] recrea, en los espacios más lejanos, nuevas modalidades de trabajo informal, intermitente, precarizado, "flexible", agotando aún más los niveles de remuneración de quienes siguen trabajando (ANTUNES, 2018, p. 26).

El autor llama la atención sobre la explosión de los nuevos proletarios de servicios y sus nuevos significados en el escenario actual, dada la informatización de la era financiera y la llamada industrialización de los servicios, como nuevos espacios posibles de generación de valor. Siendo vitales, "las TICs, que están cada vez más presentes en el mundo de la 
producción material e inmaterial y que también tipifican los servicios privatizados y mercantilizados" (Id., p.35, subrayado en el original).

Procesos que se dan en el marco histórico-social de la profundización de la crisis de sobreproducción de capital, cuya raíz se encuentra en la sobreproducción de mercancías y en la acumulación sin precedentes de capital ficticio (Chesnais, 2013). Lo que revela que el capital se encuentra nuevamente "[...] 'atrapado' por sus contradicciones, enfrentando las barreras que él mismo creó" (Id.; p.26). Su administración solo es viable en la "búsqueda incesante de superganancias, un proceso imposible sin la explotación de la fuerza laboral viva” (Id.; p.30). Esto solo agrava la situación de los trabajadores frente a las nuevas tendencias de acumulación capitalista.

En este universo, expresiones como "zerados" o zero hour contract, el trabajo de vales (por voucher) uberizado, persona jurídica sin vínculo laboral, intermitentes, flexibles, autónomos, emprendedores, subcontratados y temporales - , forman parte de nuestra vida cotidiana de forma fluida, ocultando las nuevas formas de realizar el trabajo asalariado y su disfraz - el no reconocimiento de estos vínculos es crucial para el capital. Ahora podemos ver por qué: la uberización y la intermitencia son una tendencia que debe afectar a todos los trabajadores sin distinción.

La precariedad es una de las formas históricas de objetivación de la explotación del trabajo, y no es desconocida en la trayectoria de vida de los trabajadores. Engels ${ }^{4}$, al estudiar las condiciones de vida y de trabajo del proletariado industrial en la Inglaterra del siglo XIX, ya apuntaba a este fenómeno como inherente a la dinámica de la acumulación, señalando los impactos de la revolución industrial en las condiciones de vida y de trabajo y en la subjetividad del proletariado con el advenimiento de la máquina a vapor y las máquinas procesadoras de algodón. Demostró el empobrecimiento acentuado de una clase social que se estaba constituyendo y desarrollándose a niveles cada vez más voluminosos: cuanto

4 ENGELS, Friedrich. A situação da classe trabalhadora na Inglaterra. São Paulo, Boitempo, 2010. 
más trabajaban, más riqueza generaban y más privados de los medios fundamentales de vida se volvían.

En la actualidad, la precariedad se realiza a través de nuevas mediaciones que particularizan los procesos de explotación del trabajo, dada por la amplia reestructuración productiva que introduce la subcontratación, la informalidad, la flexibilidad y la intensificación, exponiendo el motor destructivo del capital bajo la fuerza humana del trabajo, siendo despiadadamente orquestado por el capital portador de intereses.

Siendo así, es necesario considerar el papel estratégico de las TICs y su expansión ilimitada en la actualización "entre los diferentes mecanismos de acumulación creados por el capitalismo financiero de nuestro tiempo" (Antunes, 2020, p. 13), proporcionando que el tiempo de la producción y del trabajo se prolonguen, haciendo más dinámica la composición orgánica del capital. Un mosaico que profundiza el desempleo, las enfermedades, los acosos, la humillación, las condiciones infrahumanas de reproducción en el mercado, cuyo registro es el mayor empobrecimiento de los trabajadores.

\section{La tesis de la proletarización del trabajo del asistente social}

El Trabajo Social se configura en la división social del trabajo como una especialización del trabajo colectivo, perteneciendo, en términos de Antunes (2018), al “mundo capitalista de los servicios", como trabajo im-

\footnotetext{
5 Los servicios y la naturaleza de este trabajo son controvertidos, refiriéndose al debate sobre el trabajo productivo y improductivo en Marx, que no es un consenso ni siquiera en la propia tradición marxista. Para Rubin (1987, p. 277), el debate sobre el trabajo productivo "está lleno de desacuerdos y confusión conceptual [...] tanto entre marxistas como entre ellos y sus oponentes". Cabe señalar que "[...] la distinción entre trabajo productivo y improductivo no concierne al contenido, el carácter del trabajo útil o de sus productos, siendo indiferente a su naturaleza material y inmaterial [...]. En el campo de los servicios, la producción capitalista se redujo al mínimo en la época de Marx, presentándose, de manera muy limitada, en comparación con
} 
productivo. No se trata aquí de si la profesión genera valor o no, sino de la "identidad del trabajo del trabajador social, como trabajo abstracto, con el trabajo social medio: como parte alícuota del trabajo total producido socialmente. Las implicaciones del trabajo del trabajador social en el circuito del valor [...] en la sociedad del capital fetiche" (Iamamoto, 2008, p. 418).

Una especialización que viene sufriendo las determinaciones vigentes, experimentando así con el conjunto de la clase obrera la precariedad del trabajo en las diferentes instituciones de empleo, manifestada en diferentes grados y niveles. Lo que puede ser demarcado mediante diversos indicadores como salario, jornada laboral, número de enlaces laborales, formas de contratación e infraestructura para la realización del trabajo (equipamientos, instalaciones físicas, etc.).

El mercado laboral para los Trabajadores Sociales se ha modificado no solo en relación con las demandas y requisitos profesionales; está envuelto en una intensa precarización de las condiciones y relaciones laborales y en la creación de nuevos métodos de contratación y gestión de esta fuerza de trabajo.

La hipótesis es que asistimos a la proletarización del trabajo del trabajador social en dimensiones hasta ahora desconocidas en el universo profesional, demarcada por un intenso empobrecimiento de las condiciones de vida y laborales. Inicialmente, esto se puede ver por la condición salarial, pero no solo, sino también por el sugerente proceso a partir de la investigación realizada en el mercado laboral de trabajadores sociales, entre 2018-2019, en un municipio de tamaño medio del nordeste del estado de Minas Gerais, en Brasil. En ese momento, el mercado estaba conformado por 103 profesionales ${ }^{6}$, comprendiendo 44 espacios

la producción material, algo diferente a lo que ocurre hoy con el crecimiento de los servicios bajo la órbita del capital". (IAMAMOTO, 2008, p. 87).

6 La metodología de investigación es de naturaleza cuantitativa y cualitativa, utilizando dos instrumentos de recolección de datos, el cuestionario y la entrevista con guión semiestructurado. En la investigación cuantitativa participaron 47 profesionales y, a partir de estos datos, se seleccionaron 18 para la entrevista. 
ocupacionales, a través de 25 instituciones empleadoras. De estos, el $77 \%$ se encuentran en instituciones públicas, a nivel municipal, estatal y federal. Las instituciones privadas registran la presencia del 7,6\% y las instituciones sin fines de lucro el 15,4\%.

Identificamos que además de que los profesionales están subordinados a niveles salariales muy bajos, casi equivalentes a un salario mínimo, están presentes contratos temporales, subcontratos (realizados por el mismo empleador), turnos dobles y intensos, así como la tendencia a la subcontratación laboral en las UPAS (Unidades de Pronto Atendimento / Unidad de Cuidados de Emergencia), el home office en el Instituto Nacional de Seguridad Social o el trabajo por metas, entre otros. Procesos que se desarrollan en instalaciones físicas extremadamente precarias, insalubres, desprovistas de las condiciones mínimas de dignidad humana para realizar el trabajo (y incluso la ausencia de espacios físicos para realizar el trabajo), sin teléfono, entre otros insumos y equipos.

Sobre estas tendencias, como home office y el impacto de las TICs, los profesionales del INSS destacan:

El INSS está lanzando este nuevo proyecto, aún no hemos comenzado, pero no sabemos cómo sucederá aquí (Seguridad Social).

Cuando te unes, pierdes los vales de transporte, los vales de comida y gastarás tu energía, tu internet. Para respaldar el sistema INSS, debe respaldar una buena Internet, una computadora, el mantenimiento de las computadoras. Desafortunadamente, veo a colegas que lo encuentran maravilloso (Seguridad Social).

La expresión proletarización es utilizada aquí en un sentido amplio, para caracterizar las tendencias contemporáneas en el mundo del trabajo de acentuada precariedad y empobrecimiento de las relaciones laborales. La expresión proletarización proviene del latín proles (raza, linaje, familia, descendencia, hijo, posteridad) da lugar a la expresión proletariado (latín proletarĭus, $\breve{i}$, lo que es equivalente solo por cuenta 
de su prole). Se trata de un grupo de descendientes, siempre numerosos, que viven en condiciones de vida precarias, con escasas condiciones de supervivencia y sujetos a relaciones laborales degradadas. Sobre esta cuestión, Antunes dice:

Sabemos que Marx y Engels consideraban a la clase obrera y al proletariado como sinónimos. Y que, en la Europa de mediados del siglo XIX, los trabajadores asalariados que inspiraron el reflejo de ambos ganaron expresión corporal en el proletariado industrial, lo que posibilitó la dominación común y incluso indiferenciada entre la clase obrera y el proletariado (ANTUNES, 2020, p. 92).

El autor revela la explosión del nuevo proletariado de servicios y la forma en que estos trabajadores son sometidos a la informalidad, la flexibilidad, la subcontratación como tendencia general y que no perdona a ningún trabajador, o si la actividad es más intelectual o manual, si es productiva o improductiva, si es trabajo material o inmaterial. Estamos ante una forma monumental de explotación y consumo de la fuerza del trabajo que lleva a todos los trabajadores a una precariedad estructural. Son cambios que reconfiguran la división del trabajo y nos colocan frente a una nueva morfología del trabajo.

\section{Manifestaciones de proletarización en el trabajo profesional}

El trabajador social trabaja bajo el control directo del empleador, que es propietario del uso de su fuerza laboral durante un período de tiempo específico. En el camino, se identificó que la mayoría de los trabajadores están sometidos a una jornada laboral de 30 a 40 horas, pero también a través de la subcontratación llegan a 55. Para Dal Rosso (2016, p. 33), la jornada laboral en el mundo actual se manifiesta a través de dos 
elementos: duración e intensidad7, "la duración de la jornada laboral y su grado de intensidad, resulta que en la actualidad convergen tendencias que acumulan repercusiones sobre la explotación del trabajo", ya que "la intensificación del trabajo y el alargamiento de la jornada son condiciones que se pueden vivir juntas siempre y cuando esta unión no ponga en riesgo la vida del trabajador por su excesiva participación en el trabajo "(Id.).

Soy sirviente fijo para el puesto, pero también tengo contrato temporal con el gobierno municipal. A través de mi salario se hace el cálculo, en base a lo que gano por día y por hora y recibo proporcionalmente las horas trabajadas en el nuevo contrato. Es una subcontratación dentro de mi contrato, donde tengo que estar sujeto a los intereses de aquí y de la institución a la que estoy adscrita (designada) (Asistencia Social).

En la asistencia (Trabajo) social, estos profesionales trabajan 10 horas diarias y 50 horas semanales, además de señalar perversamente el valor de la fuerza laboral y su devaluación monetaria en el mercado. Esta tendencia está presente en salud, bajo los términos de la contratación para ejercer una función dual, como técnico y gerente de servicios, expresando la multifuncionalidad de la fuerza laboral y sin líneas divisorias cuando se inicia la labor de técnico y el de coordinación. El profesional es contratado para una carga de trabajo diaria de 8 horas y debe administrarla entre las dos funciones.

\footnotetext{
Según Dal Rosso (2008), intensidad y productividad no son sinónimos. Si el concepto de productividad nace en el marco de la economía como una forma de considerar el trabajo más productivo, en los "resultados que resultan de los avances realizados únicamente en los medios materiales con los que se realiza el trabajo. A este aumento lo llamamos el resultado de la productividad" (Id.; p. 167). La intensidad está relacionada con el acto de trabajar y el grado de gasto de fuerza y energía que utiliza el trabajador en el trabajo concreto, efectuado en la dimensión del trabajo abstracto. La forma en que se efectúa la intensidad "se transfiere con el acto de comprar y vender la mano de obra de las manos del vendedor a las manos del comprador" (Id.; p. 24).
} 
Se trata de procesos precarios que encogen el tiempo libre y se manifiestan en los diferentes espacios de trabajo, como se indica a seguir:

La demanda que se presenta a las personas es muy compleja y complicada, y la demanda supera nuestras horas de trabajo. A veces la gente pasa unas horas más aquí en el trabajo, mi tiempo de trabajo es hasta las 13:00, a veces salgo a las 15:00. No puedo simplemente decirle al usuario: pegue esto aquí y listo. (Asistencia Social).

Hay de 15 a 20 servicios solo por la mañana. No es posible determinar el horario de cada servicio, ya que cada ítem requiere algo diferente, y cuando el usuario elige ser atendido él quiere ser escuchado. Entonces pierdes algo de tiempo por esta escucha, tanto es así que se dañan los últimos servicios con respecto a la profundización. Yo también estoy cansada, ya no puedo razonar - ni yo ni mi colega. La gente aprovecha este momento de atención, porque observa que esta continuidad de acompañamiento, que es obra de CRAS, queda difícil, ya que quedamos inmersos en esta demanda. Sería necesario tener otro equipo con más asistentes sociales y psicólogos para manejarlo, tendría que doblarse para acompañar al usuario de una manera apropiada a la política. El horario es hasta el 12:00, pero en días de servicio es imposible, salimos a las 13:00. No podíamos parar a tomar un café o ir al baño; A veces, cuando uno se levanta a buscar agua, aprovecha y se la lleva a otro, por cuenta del poco tiempo, del apuro de tiempo. (Asistencia Social).

Los informes anteriores son de profesionales sometidos a contratos temporales, 12 meses y jornada diaria de 06 horas. Es interesante notar que, en el relato abajo, uno de ellas destaca el trabajo extra como forma de sensibilizar a la institución para la renovación de su contrato.

A veces llego pensando así: ¿será que si voy más allá pueden renovar mi contrato? El colega dice: "Fulano de tal, esto no es tu responsabilidad, adelante". Pero tengo miedo de tener una queja y tener problemas con el contrato en el futuro. Ya ha habido elogios de la institución y de los usuarios (Asistencia Social). 
La mayoría de los trabajadores sociales son contratados y es muy difícil. Cada primer día de cada año es un peligro, no sabemos si se renovará el contrato. La incertidumbre y la inseguridad son grandes. Llega el primer día de cada año, no sabemos si vamos a trabajar, sobre todo en un cambio de gobierno (Asistencia Social).

Los testimonios revelan el aumento de la precariedad y el nivel de degradación del trabajo y el indicador de la erosión de los empleos estables. Se combinan elementos, para utilizar una expresión de Antunes (2018), de una fenomenología de la sobreexplotación del trabajo, que atestigua una tendencia casi homogénea de contratación de fuerza de trabajo para todas las ramas de la producción social, flexibilizando, desregulando y adaptando las relaciones laborales a los despliegues de la reestructuración productiva.

El profesional define lo que sería para él la precariedad o sus manifestaciones:

El tema del salario es una expresión de la precariedad, lamentablemente lo vemos. No estoy en la Asistencia Social, el salario de la Asistencia desde hace 12 años es el mismo en la ciudad, $R \$$ 1.080,00. Hace 12 años estaba haciendo una pasantía y el salario era ese. Diez años después de graduarme, hice dos años de pasantía y el tema del salario no ha cambiado. También hay el hecho de que compartimos habitación con más de un técnico, por ejemplo, y eso es una precariedad. Hay muchas situaciones, como el problema del teléfono, que no tenemos. (Salud).

Llegamos a los lugares para realizar las inspecciones técnicas a través del guión de acción de la Coordinación, y se percibe el desguace de la política pública, además de las pésimas condiciones laborales y salariales de los profesionales. Pasa por el tema del salario, por la rotación del trabajo. Vas allí hoy, hay un equipo, si la ciudad de al lado ofrece un mejor salario, el profesional se muda a la otra ciudad. Esto pasa mucho. Llegamos a una entidad y decimos: “estás aquí?" Luego pasan tres meses y vamos a hacer otras inspecciones, la persona ya está en otro municipio, puramente por motivos salariales (Socio jurídico). 
Para el profesional, el control sobre el trabajo es una forma de intensificar la jornada laboral y se manifiesta de forma diferente en cada espacio socio laboral:

Tenemos el objetivo de la Coordinación. Tenemos un plan, por lo que dentro de ese plan intentamos lograr lo planeado. Otro objetivo a cumplir se refiere al cumplimiento de los plazos contenidos en las órdenes del Promotor de justicia. Sin embargo, los plazos son razonables y flexibles, pudiendo negociarse ante una situación que justifique la ampliación del plazo (Socio jurídico).

En Nasf, tenemos un objetivo que cumplir. Cada Trabajador Social, con una carga de trabajo de 30 horas, debe realizar, en un mes, al menos 38 consultas individuales. De hecho, estas 38 asistencias se refieren a la cantidad que debe realizar cada técnico del equipo [el cálculo es el siguiente: hay 7 técnicos, por lo que el equipo debe realizar 266 asistencias]. Entonces tengo que hacer al menos 38 llamadas al mes. A la institución solo le interesa la cantidad de atención que se lanzará en el sistema SUSfácil, no se mira qué demanda se atendió, si se resolvió. No miran la calidad, quieren saber la cantidad en el sistema (Salud).

$\mathrm{El}$ equipo tiene que realizar mensualmente 20 visitas a familias. Dividimos esta cantidad entre los 6 técnicos para poder cumplir con la meta mensual. Necesitamos lanzar en una hoja de cálculo que ya pertenece al sistema (Socio jurídico).

En el INSS, este proceso se acentúa más, con un impacto en el salario. Los profesionales informan que la institución establece una meta individual (cualitativa) y una colectiva que deben cumplirse simultáneamente para que el servidor pueda elevar el salario mensual a través de bonificaciones. "Respondiendo a la demanda, tendremos el salario, si no lo cumplimos habrá una reducción del salario” (Seguridad Social).

El profesional se refiere a la meta cualitativa, que corresponde al 20\% por debajo del salario base, como se explica a continuación: 
Es porque nuestro salario base es de ochocientos reales aproximadamente, el resto es una bonificación. El impacto está en la gratificación y no en el salario base. Nuestro mayor salario proviene de la gratificación. Si tiene que elegir entre el salario base y el bono, es mejor quedarse con el bono. Ya es una estrategia de la institución, porque se mantiene el salario base, no se cambia (Seguridad Social).

Las bonificaciones tienen un impacto salarial de más del 70\%. La composición es la siguiente:

El objetivo colectivo que no es del Trabajo Social, pertenece a los servidores del INSS, que es el 80\%. Este objetivo colectivo coincide, en esto, para comprimir los índices, y luego ¿qué pasa? Les doy un ejemplo, es de toda la gerencia, de las 13 agencias: supongamos que las 12 agencias están cumpliendo el objetivo y la ciudad de Teófilo Otoni no. Pero Teófilo Otoni, como es la agencia más grande, baja la meta de todos y impacta en el número de todas las gestiones. Además, el no cumplir con el objetivo de una agencia más pequeña puede afectar el resultado final. ¿Qué hace eso? A muchos trabajadores les hace pensar: "bueno, yo estoy haciendo mi parte, pero tengo que exigirle a otro colega que no está haciendo la suya”. Es una lógica perversa, de inspeccionar el trabajo de otros. Un servidor supervisa al otro. Eso es el $80 \%$ dela meta. Ahora, tiene el $20 \%$ que es individual, que es su evaluación individual. Que lo realiza el jefe inmediato, en este caso, el gerente de la sucursal (Seguridad Social).

La valoración del 20\% que forma parte de la meta es una valoración cualitativa, diferente de la valoración colectiva, que es cuantitativa y tiene en cuenta si el servidor público es susceptible a cambios, si es flexible a las normas de la institución, por ejemplo. Veamos que dice el profesional:

Si usted pierde 1 punto, no tiene un impacto directo en su salario, como sí ocurre en el otro. La cuantitativa es la meta terrible, que obliga a un colega a inspeccionar el trabajo del otro [...] cuando dije que hay un tiempo de espera promedio, que es de 45 días, te dan una contraseña, estás programado 
para las 8:00 am en la mañana y a las 9:00 am no te respondí. Miden, ellos miden todo esto, el tiempo de espera del usuario. ¡Oye, guau! Pero el tipo está tardando un poco en llamar. Por ejemplo, tenemos 1 hora para la valoración social, pero hay casos en los que voy a dedicar 45 minutos, hay casos en los que voy a dedicar 1 hora y 15 minutos, porque haré redireccionamentos (focalización), necesitaré socializar la información, algo que también ocurre en el cuidado individual. Usted orienta hacia el derecho a otro beneficio de alguien de la familia que esté acompañando al usuario, o una serie de preguntas, por lo que esto es tan difícil (Seguridad Social).

Añaden que la institución no considera:

Si tienes un horario completo, contestando, cuidando, haciendo su trabajo, si bloqueaste el horario para hacer esta planificación, esto no se valora. Para la institución, el profesional no está haciendo nada. Aparte de la información que el profesional proporciona por teléfono a los profesionales - esto no cuenta; por correo electrónico, envías un correo electrónico, das la respuesta. Esto no se mide (Seguridad Social).

Es importante destacar que, para Antunes (2018), la gestión por metas es consecuencia de la reestructuración productiva, difundida, sobre todo, a partir de la década de los 80 , en pleno auge del fortalecimiento de la lógica de racionalización de la economía global, basada en incrementar la medición por resultados, ya esbozada por las configuraciones colocadas en el mundo capitalista a partir de los años setenta.

Las condiciones salariales de los profesionales son sumamente precarias, revelando la devaluación monetaria de esta fuerza especializada en el mercado. Encontramos que el 70\% recibe ingresos brutos mensuales casi equivalentes al salario mínimo (basado en el año 2019), la gran mayoría de los cuales son trabajadores de asistencia social, con el salario más bajo. En salud, los trabajadores fijos rondan los tres sueldos. En los hospitales filantrópicos, es incluso superior a dos salarios mínimos. En los hospitales privados, puede alcanzar un rango de tres a cuatro salarios 
mínimos. En educación, encontramos los salarios más altos, en el caso del trabajo docente, delimitado por la titulación, que van desde cinco a trece salarios mínimos. Aunque en la educación privada, el técnico de asistencia al estudiante se encuentra en un nivel superior a dos salarios mínimos. Los salarios más altos, fuera del área de educación, se encuentran en el ámbito/en lo socio jurídico, superiores a nueve salarios mínimos, sin embargo, para los profesionales que laboran en seguridad pública, esta cifra baja a tres. En seguridad social, la remuneración es equivalente a la de los técnicos del Ministerio Público, sin embargo, alcanzar estas cifras está condicionado al logro de las metas, como se explicó anteriormente.

En este universo de trabajo también están presentes la escasez de recursos y la precariedad de las instalaciones físicas. El espacio físico de las instituciones que albergan al profesional se estructura a raíz de la precariedad de las políticas sociales. Identificamos espacios improvisados, con poca ventilación e iluminación - además de la insuficiencia acústica, que compromete el secretismo en el acto del cuidado asistencial y, también, la ausencia de este espacio:

Hoy perdimos esta sala, y hoy deambulamos por el PSF (Programa de Salud Familiar). Para la atención en cada PSF, a veces la enfermera sale de su habitación y nos presta el espacio, o usamos la sala médica, si en ese día no hay atención, [...] entonces hay esas comunidades que tienen una iglesia, o una escuela, o un tribunal, que se presta al municipio para realizar las actividades del PSF. [...] pero estos lugares donde realizamos actividades no cuentan con estructura física adecuada. En una iglesia evangélica, por ejemplo, donde tenemos un grupo, si hay un velorio en ese lugar, llegas y no puedes realizar la actividad programada (Salud).

Aún en las instalaciones físicas, los profesionales denuncian la precaria estructura de transporte para realizar visitas domiciliarias y institucionales. En el caso de Cras y Cress (Centro de Referencia de Asistencia Social y Consejo Regional de Trabajo Social), los profesionales informan que cuentan con transporte para realizar visitas domiciliarias solo una 
vez a la semana, esto es cuando la institución puede garantizarlo. Esta infraestructura, necesaria para que el trabajo se realice, cuando no se accede por el profesional o se accede en condiciones limitadas, contribuye a la acumulación de tareas, dado el flujo diario de atendimientos en la institución.

Entre todos los procesos que desafían al Trabajo Social en el mercado laboral, también cabe destacar los impactos de estas condiciones en la salud de los trabajadores. Se ha constatado que las consecuencias son dolencias, que se manifiestan en enfermedades como la depresión y la fibromialgia, como se muestra a continuación:

Hoy estoy en tratamiento médico, pero hoy veo que esto es un reflejo de esta acumulación de trabajo, como la fibromialgia - enfermedades que empeoran cuando tienes cierto grado de estrés. Me siento un poco en esa línea, porque ya estoy un poco cansada. Al contactar el equipo, otros compañeros se quejan de estos temas, también del peso de la carga de trabajo (Asistencia Social).

Son 30 horas semanales según lo que establece la ley, sin embargo, el problema aquí es que el flujo de asistencia suele ser muy grande en ocasiones y trato de controlar esta asistencia, que está de acuerdo con lo que logro hacer. Sobrecarga, hoy no digo que la tengo, porque hoy estoy manejando mejor esta carga de trabajo, pero ni siquiera sé si la tomo en cuenta, pero me enfermé el año pasado. Incluso tuve un diagnóstico de síndrome de Burnout y la aparición de depresión por sobrecarga (Educación).

Lo anterior contribuye a la afirmación de Antunes (2018, p. 142), de que "la presión por una capacidad de respuesta inmediata de los trabajadores a las demandas del mercado [...] ha ido convirtiendo, gradualmente, el entorno laboral en un espacio de enfermedad". Estando presente "la progresiva reducción o ausencia del control mínimo de los trabajadores sobre el proceso de trabajo. Provocando enfermedades como problemas osteoarticulares, disturbios gastrointestinales, cardiovasculares, de salud mental y accidentes laborales" (Id.; p. 143). 
Son estos procesos continuos, presentes en el mercado de los trabajadores sociales, que sugieren la tesis de la proletarización del trabajo profesional. Lo que en realidad es una tendencia hacia la reproducción del trabajo en la sociedad de clases, revelando uno de los retratos del mundo del trabajo en sus nuevas tendencias y incidencias en el Trabajo Social, pero también en la clase obrera en su conjunto.

\section{Conclusión}

El análisis de las condiciones y relaciones laborales en las que se insertan hoy los trabajadores sociales están determinadas por las nuevas demandas del capital. Así, la precariedad se superpone con la informalidad, la intensificación, la subcontratación y la proletarización del trabajo. Las condiciones y las relaciones de trabajo vividas por los profesionales articulan un conjunto de mediaciones que interfieren en el procesamiento de la acción profesional, ubicándose en el marco contradictorio que es la sociedad burguesa en su totalidad concreta.

La precariedad en el capitalismo contemporáneo explicita la proletarización generalizada de todos los trabajadores, sin distinción, acentuando la pauperización, la expropiación, ampliando las filas del ejército industrial de reserva y imponiendo la disponibilidad perpetua para el trabajo (Antunes, 2018). Al mismo tiempo, en la realidad concreta, hemos identificado innumerables trabajadores desempleados, subempleados, intermitentes, uberizados, subcontratados, etc. Procesos que expresan la redefinición de las condiciones de vida y de trabajo en la actualidad.

\section{Referencias}

ABÍLIO, Ludmila Costhek. Uberização: Informalização e o trabalhador just-in-time. Estudos Avançados. vol.34 no.98. São Paulo: Jan. / Abr. 2020. Disponible en https://www. scielo.br/scielo.php?script=sci_arttext\&pid=S0103-40142020000100111.Acceso en: 10 de mayo de 2020. 
ANTUNES, Ricardo. O privilégio da servidão: o novo proletariado de serviços. 2. ed. rev. e ampl. São Paulo: Boitempo, 2018.

ANTUNES, Ricardo. Trabalho intermitente e uberização do trabalho no limiar da Indústria 4.0. In.: ANTUNES, Ricardo (Org.). Uberização, trabalho digital e indústria 4.0. São Paulo: Boitempo, 2020.

CHESNAIS, François. O capital portador de juros: acumulação, internacionalização, efeitos econômicos e políticos. In: CHESNAIS, François. (Org.) A finança mundializada: raízes e políticas, configuração, consequências. São Paulo: Boitempo, 2005.

CHESNAIS, François. As raízes da crise econômica mundial. Revista Em Pauta, Rio de Janeiro, n. 31, p. 21-37, 2013.

DAL ROSSO, Sadi. Teoria do valor e trabalho produtivo no setor de serviços. Caderno CRH. Salvador, v. 27, n. 70, 2014. Disponible en http://www.cadernocrh.ufba.br/viewarticle. php?id=1359\&layout=abstract. Acceso en: 10 de Jun. de 2016.

DAL ROSSO, Sadi. Mais trabalho!: A intensificação do labor na sociedade contemporânea. São Paulo: Boitempo, 2008.

IAMAMOTO, Marilda. Serviço Social em tempo de capital fetiche:capital financeiro, trabalho e questão social. 2. ed. São Paulo: Cortez, 2008.

MARX, Karl. O capital: crítica da economia política. São Paulo: Nova Cultural, 1986. (Livro terceiro, vol. IV).

RUBIN, Isaak Illich. A teoria do valor. São Paulo: Editora Polis, 1987.

\section{Sobre el Autor}

María Angelina B. De Carvalho de A. Camargo - Trabajadora social, Doctora en Trabajo Social, profesora del Departamento de Trabajo Social, investigadora del Centro de Estudios del Trabajo (NET / UFES).

Correo electrónico: mariaangelinacarvalho@uol.com.br 